Journal of Patient-Centered

Volume 3

Issue 2 - Infectious Disease

Article 4

4-22-2016

\title{
Clinical Approach to Nonresponsive Pneumonia in Adults Diagnosed by a Primary Care Clinician: A Retrospective Study
}

Kiley B. Vander Wyst

Jessica J. F. Kram

Dennis J. Baumgardner

Follow this and additional works at: https://aah.org/jpcrr

Part of the Bacterial Infections and Mycoses Commons, Primary Care Commons, and the Respiratory Tract Diseases Commons

\section{Recommended Citation}

Vander Wyst KB, Kram JJ, Baumgardner DJ. Clinical approach to nonresponsive pneumonia in adults diagnosed by a primary care clinician: a retrospective study. J Patient Cent Res Rev. 2016;3:79-89. doi: 10.17294/2330-0698.1211

Published quarterly by Midwest-based health system Advocate Aurora Health and indexed in PubMed Central, the Journal of Patient-Centered Research and Reviews (JPCRR) is an open access, peer-reviewed medical journal focused on disseminating scholarly works devoted to improving patient-centered care practices, health outcomes, and the patient experience. 


\title{
Clinical Approach to Nonresponsive Pneumonia in Adults Diagnosed by a Primary Care Clinician: A Retrospective Study
}

\author{
Kiley B. Vander Wyst, MPH,, ${ }^{1,2}$ Jessica J. F. Kram, MPH, ${ }^{1,2}$ Dennis J. Baumgardner, MD ${ }^{1,2,3}$ \\ ${ }^{1}$ Center for Urban Population Health, Milwaukee, WI \\ ${ }^{2}$ Aurora University of Wisconsin Medical Group, Aurora Health Care, Milwaukee, WI \\ ${ }^{3}$ Department of Family Medicine and Community Health, University of Wisconsin School of Medicine and Public \\ Health, Madison, WI
}
Purpose Community-acquired pneumonia (CAP) is commonly diagnosed in the primary care setting. Management of nonresponsive pneumonia (NRP), i.e. failure to respond to CAP treatment, is not clearly understood. The purpose of this study was to describe the initial work-up and treatment of CAP in the ambulatory primary care setting and to determine relative proportion of, diagnostic approach to and treatment of NRP.

Methods We retrospectively studied adult patients diagnosed with CAP within our large, integrated health care system from October 2006 through July 2013. Cases were defined as patients with CAP who worsened after 4 days, or did not improve within 10 days, of antibiotic treatment. Controls were CAP patients who did not meet case definition. Mann-Whitney and t-tests were used to analyze continuous variables. Chi-square or Fisher's exact test was used to analyze categorical variables. Significant variables were used to construct a multivariable logistic regression model.

Results Of 250 total patients studied, there were 85 cases and 165 controls. The case population was significantly older (59 \pm 16 vs. $53 \pm 19$ years, $P=0.02$ ). Multivariable logistic regression revealed former smoker $(P<0.01)$, initial presentation to urgent care $(P=0.02)$ and myalgia $(P=0.003)$ as predictors of NRP. Chest X-rays were more commonly ordered for cases at initial visit ( $80 \%$ vs. $68 \%, P=0.06)$. Overall, $24 \%$ of patients had additional testing at the initial visit ( $39 \%$ of cases vs. $16 \%$ of controls, $P<0.001)$. Additionally, a higher proportion of cases underwent antibiotic change at their first $(62 \%$ vs. $15 \%, \mathrm{P}<0.001)$ or second (47\% vs. $5 \%, \mathrm{P}<0.001$ ) follow-up visit.

Conclusions Patients with NRP tended to be former smokers, report myalgia and/or present to urgent care. The majority of providers conducted chest X-rays, but no further pneumonia testing, at the initial visit. Further study is needed to determine if this strategy leads to delayed etiologic diagnosis and definitive treatment. (J Patient Cent Res Rev. 2016;3:79-89.)

Keywords community-acquired pneumonia; nonresponsive pneumonia; nonresponding

Community-acquired pneumonia (CAP) is a common infectious disease that is frequently diagnosed by primary care clinicians. In the United States, more than 4 million cases of pneumonia present to ambulatory health centers annually and rely on primary care clinicians (i.e. those in family medicine, internal medicine and urgent care) as their first point of contact. ${ }^{1}$

Correspondence: Dennis J. Baumgardner, MD, Aurora Sinai Medical Center, 1020 N. 12th Street, \#4180, Milwaukee, WI, 53233, T: 414-219-5191, F: 414-219-3116, Email: dennis.baumgardner@aurora.org
A 2002 publication from the Agency for Healthcare Research and Quality emphasized the safety and cost savings of outpatient versus inpatient treatment for CAP (average cost of outpatient case was $\$ 300$ vs. $\$ 5,700$ for inpatient case). ${ }^{2}$ Older studies also have confirmed the safety of initial outpatient treatment for CAP in persons deemed to be at low risk for complications..$^{3-5}$ Nonetheless, the primary care setting creates a difficult environment in which to diagnose pneumonia due to the reliance on patient history and physical examination and, frequently, the lack of on-site chest radiographs. ${ }^{6}$ 
Nonresponsive pneumonia (NRP) occurs when treatment for CAP fails despite an administered antibiotic regimen, and results in worsening symptoms or delayed achievement of clinical stability. ${ }^{7}$ NRP is multifactorial and associated with increased morbidity, mortality and costs. ${ }^{7-11}$ Recent studies of NRP have all involved hospitalized patients..$^{7-10,12-17}$ Thus, little is known about NRP in patients initially seen in a primary care ambulatory clinic.

The purpose of this study was to assess how primary care clinicians managed CAP cases that presented in the ambulatory setting and determine the relative proportion and characteristics of NRP in the outpatient population. In addition, we aimed to describe how NRP initially presenting in the outpatient setting is addressed through additional diagnostic work-up or changes in treatment.

\section{METHODS}

\section{Data Sources and Subject Selection}

A retrospective unmatched case-control study of 250 subjects aged 18 years or more who had CAP diagnosed by a primary care clinician in an outpatient facility from October 2006 through July 2013 was conducted. Randomly sorted electronic medical records were obtained by the research analytics team at our institution, a large health system that includes 15 hospitals and more than 150 outpatient clinics. Subjects were identified from all outpatient facilities by ICD-9 pneumonia diagnostic codes $480-486$ (and subsets). Patients who had documented CAP diagnosis by either clinical or radiographic impressions were included in this study. Excluded patients were those who had no substantiation of CAP diagnosis by the treating clinician, initially presented to an emergency department or a non-primary care specialist, were ultimately diagnosed with medical facility-acquired pneumonia, or had incomplete records. Additionally, patients with any of the following diagnoses were excluded: cancer, bronchiectasis, blood dyscrasia, tuberculosis, HIV/AIDS or tracheostomy/ventilator dependence. Pregnant women also were excluded.

Cases of NRP were defined as individuals with CAP who had worsening vital signs, symptoms or clinical findings after 4 days, or who did not improve within 10 days, of antibiotic treatment. Control subjects were
CAP patients who did not meet the case definition (i.e. had stable signs or symptoms within 4 days of antibiotic treatment and/or improved within 10 days of antibiotic treatment). Patients with CAP who were treated with antibiotics and not expected to make a follow-up visit but advised to return if there was no improvement were considered control subjects if they did not further encounter our integrated health system for that pneumonia illness.

Variables obtained from the medical records included basic demographic data, smoking status, comorbid conditions, presenting and follow-up respiratory and constitutional signs and symptoms, vital signs, timing of follow-up visits, related laboratory and radiologic test results, type and timing of antibiotic therapy, and the final most specific diagnosis for the medical condition that prompted the initial clinical or radiologic diagnosis of pneumonia. For purposes of this retrospective study, we considered clinical signs and symptoms present if they were recorded in the medical record and absent if they were not. The first author either personally reviewed each medical record examined for this study or closely supervised the record review process. Subjects with uncategorized clinical features were included following consensus by the first and third authors.

All activities were reviewed and approved by the local institutional review board.

\section{Statistical Analysis}

Minitab $^{\circledR}$ statistical software (Release 13, State College, PA) was used for data analysis. Summary statistics were calculated. Categorical data was analyzed using chi-square tests with Yates' correction or Fisher's exact test, as appropriate. Continuous variables were analyzed using two-sample t-tests or the Mann-Whitney test. Binary logistic regression was used for multivariable analysis of NRP cases versus controls, utilizing only variables that were significant on univariable analysis. P-values less than 0.05 were considered statistically significant.

\section{RESULTS}

A total of 991 electronic medical records of unique adult patients associated with a diagnosis of pneumonia in an outpatient department of our 
health system were identified. Of those records, 398 were excluded for lacking confirmation of clinician diagnosis of acute CAP. Of the 593 patients with CAP, 84 were excluded due to incomplete medical records and 259 were excluded due to initial presentation to a specialist physician or emergency department and/or other exclusion criteria detailed in Methods. Therefore, 250 patients met study inclusion criteria.

There were 85 cases of NRP, or $34 \%$ of those with CAP originally diagnosed in an outpatient facility by the primary care clinician. NRP cases were compared to the 165 control patients with CAP (Table 1). Our study population was predominantly Caucasian (88\%), female (54\%) and nonsmokers (76\%), and most often initially presented to a family medicine clinic
(43\%). Specificity of initial pneumonia diagnosis did not vary between controls and cases, with $86 \%$ of controls and $85 \%$ of cases given "communityacquired pneumonia," "pneumonia not otherwise specified" or related codes. Due to the fact that our medical system was continually adding primary care clinics to the electronic medical record during the study time period, $70 \%$ of included subject records were from the years 2012-2013. Cases did not differ from controls with respect to seasonal distribution using National Weather Service definitions ${ }^{18}$ (26\% vs. $34 \%$ for December-February, $45 \%$ vs. $38 \%$ for March-May, $16 \%$ vs. $15 \%$ for June-August, 13\% vs. $13 \%$ for September-November; $\mathrm{P}=0.59)$, nor by proportion seen during cold weather months ( $54 \%$ vs. $56 \%$ for October-March, $\mathrm{P}=0.77$ ).

Table 1. Comparison of features of subjects with CAP: cases vs. controls

\begin{tabular}{|c|c|c|c|c|}
\hline Feature & $\begin{array}{l}\text { NRP cases } \\
\quad(N=85)\end{array}$ & $\begin{array}{l}\text { CAP controls } \\
(\mathrm{N}=165)\end{array}$ & $\begin{array}{l}\text { Odds } \\
\text { ratio }\end{array}$ & $\begin{array}{l}\text { All subjects } \\
\quad(N=250)\end{array}$ \\
\hline Mean age $\pm S D$, years & $58.8 \pm 15.5$ & $53.4 \pm 18.8$ & $0.98^{*}$ & $55.3 \pm 17.9$ \\
\hline Female & $46(54 \%)$ & $90(55 \%)$ & & $136(54 \%)$ \\
\hline \multicolumn{5}{|l|}{ Race/ethnicity } \\
\hline White & $79(93 \%)$ & $141(85 \%)$ & 2.24 & $220(88 \%)$ \\
\hline Black & $3(4 \%)$ & $10(6 \%)$ & 0.57 & $13(5 \%)$ \\
\hline Hispanic & $2(2 \%)$ & $9(5 \%)$ & 0.42 & $11(4 \%)$ \\
\hline Other & $1(1 \%)$ & $5(3 \%)$ & 0.38 & $6(2 \%)$ \\
\hline Current smoking & $18(21 \%)$ & $41(25 \%)$ & 0.94 & $59(24 \%)$ \\
\hline Former smoker & $38(45 \%)$ & $42(25 \%)$ & $2.37^{\dagger}$ & $80(32 \%)$ \\
\hline Asthma & $16(19 \%)$ & $36(22 \%)$ & 0.83 & $52(21 \%)$ \\
\hline Chronic bronchitis & $6(7 \%)$ & $8(5 \%)$ & 1.49 & $14(6 \%)$ \\
\hline COPD & $15(18 \%)$ & $22(13 \%)$ & 1.39 & $37(15 \%)$ \\
\hline Other lung disease & $6(7 \%)$ & $4(2 \%)$ & 3.06 & $10(4 \%)$ \\
\hline Chronic sinusitis & $6(7 \%)$ & $7(4 \%)$ & 1.71 & $13(5 \%)$ \\
\hline Congestive heart failure & $6(7 \%)$ & $8(5 \%)$ & 1.49 & $14(6 \%)$ \\
\hline Other heart disease & $19(22 \%)$ & $23(14 \%)$ & 1.78 & $42(17 \%)$ \\
\hline Chronic kidney disease & $9(11 \%)$ & $7(4 \%)$ & 2.67 & $16(6 \%)$ \\
\hline Diabetes mellitus & $17(20 \%)$ & $25(15 \%)$ & 1.40 & $42(17 \%)$ \\
\hline Urgent care & $28(33 \%)$ & $33(20 \%)$ & $1.96^{\ddagger}$ & $61(24 \%)$ \\
\hline
\end{tabular}

Values are presented as $n(\%)$ unless otherwise noted.

${ }^{*} P=0.02$, two-sample $t$-test.

${ }^{\dagger} P=0.003$, chi-square test with Yates' correction.

${ }^{\ddagger} P=0.03$, chi-square test with Yates' correction.

$\S$ Patients who presented to urgent care for initial diagnosis (vs. office setting).

CAP, community-acquired pneumonia; COPD, chronic obstructive pulmonary disease; NRP, nonresponsive pneumonia; $S D$, standard deviation. 
On univariable analyses, demographic data, recorded clinical signs and initial diagnostic testing showed significant associations with NRP (Tables 2 and 3). The NRP case group was significantly older $(58.8 \pm$ 15.5 vs. $53.4 \pm 18.8, \mathrm{P}=0.02)$, had a higher proportion of former smokers ( $45 \%$ vs. $25 \%, \mathrm{P}=0.003)$ and was more likely to initially present to an urgent care setting ( $33 \%$ vs. $20 \%, \mathrm{P}=0.03$ ). Patients with NRP were significantly more likely than control patients to present with myalgia ( $28 \%$ vs. $15 \%, \mathrm{P}=0.01)$. The mean duration of cough was longer in cases compared to controls, but this difference was not significant (11.7 vs. 9.5 days, $\mathrm{P}=0.09)$. Median respiratory rate was higher and median oxygen saturation was lower in NRP patients; however, not all patients had these vital signs recorded (Table 3).

Chest X-rays were more commonly ordered for cases than controls at the initial visit, but this difference was not significant ( $80 \%$ vs. $68 \%, \mathrm{P}=0.06)$. Initial chest X-rays were no more likely to be ordered in urgent care than an office setting $(74 \%$ vs. $71 \%$, $\mathrm{P}=0.8)$ or to be read as negative ( $7 \%$ vs. $16 \%, \mathrm{P}=0.5)$. Initial radiographs were not significantly less likely to be read as negative for cases compared to controls $(6 \%$ [4/68] vs. $13 \%$ [15/112], $\mathrm{P}=0.1)$. Overall, $24 \%$ of the patients had additional testing at the initial visit, $39 \%(n=33)$ of cases and $16 \%(n=27)$ of controls $(\mathrm{P}<0.001)$. Specific types of additional testing did not differ significantly, with cases undergoing more biochemical ( $33 \%$ vs. $26 \%, \mathrm{P}=0.73)$ and hematological ( $36 \%$ vs. $29 \%, \mathrm{P}=0.78)$ laboratory tests than controls and controls undergoing more radiographic (including X-rays and $\mathrm{CT}$ scans, 26\% vs. $18 \%, \mathrm{P}=0.68)$ and microbiologic $(19 \%$ vs. $12 \%$, $\mathrm{P}=0.72$ ) tests than cases.

Only $1 \%$ of all subjects had an initial sputum culture and gram stain. At the initial visit, 1 NRP case and 4 controls had Streptococcus pneumoniae antigen testing,

Table 2. Comparison of presenting symptoms of subjects with CAP: cases vs. controls

\begin{tabular}{|c|c|c|c|c|}
\hline Symptom & $\begin{array}{l}\text { NRP cases } \\
\quad(\mathrm{N}=85)\end{array}$ & $\begin{array}{l}\text { CAP controls } \\
(\mathrm{N}=165)\end{array}$ & $\begin{array}{l}\text { Odds } \\
\text { ratio }\end{array}$ & $\begin{array}{c}\text { All subjects } \\
(\mathrm{N}=250)\end{array}$ \\
\hline Fever & $40(47 \%)$ & $73(44 \%)$ & 1.12 & $113(45 \%)$ \\
\hline Chills & $25(29 \%)$ & $47(28 \%)$ & 1.05 & $72(29 \%)$ \\
\hline Cough & $78(92 \%)$ & $160(97 \%)$ & 0.35 & $238(95 \%)$ \\
\hline $\begin{array}{l}\text { Mean duration of } \\
\text { cough } \pm S D \text {, days }\end{array}$ & $11.7 \pm 9.9$ & $9.5 \pm 8.8$ & & $10.2 \pm 9.2$ \\
\hline Hemoptysis & 7 (8\%) & $7(4 \%)$ & 2.03 & $14(6 \%)$ \\
\hline Chest pain & $19(22 \%)$ & $35(21 \%)$ & 1.07 & $54(22 \%)$ \\
\hline Chest congestion & $21(25 \%)$ & $40(24 \%)$ & 1.03 & $61(24 \%)$ \\
\hline Dark-colored sputum & $35(41 \%)$ & $86(52 \%)$ & 0.64 & $121(48 \%)$ \\
\hline Dyspnea & $41(48 \%)$ & $76(46 \%)$ & 1.09 & $117(47 \%)$ \\
\hline Head congestion & $17(20 \%)$ & $38(23 \%)$ & 0.84 & $55(22 \%)$ \\
\hline Sinus pain & $7(8 \%)$ & $20(12 \%)$ & 0.65 & $29(12 \%)$ \\
\hline Rhinorrhea & $13(15 \%)$ & $44(27 \%)$ & 0.5 & $57(23 \%)$ \\
\hline Sore throat & $18(21 \%)$ & $41(25 \%)$ & 0.81 & $59(24 \%)$ \\
\hline Night sweats & $12(14 \%)$ & $25(15 \%)$ & 0.92 & $37(15 \%)$ \\
\hline Fatigue & $29(34 \%)$ & $45(27 \%)$ & 1.38 & $74(30 \%)$ \\
\hline Malaise & $20(24 \%)$ & $28(17 \%)$ & 1.51 & $48(19 \%)$ \\
\hline Myalgia & $24(28 \%)$ & $24(15 \%)$ & $2.31^{*}$ & $48(19 \%)$ \\
\hline Headache & $14(16 \%)$ & $33(20 \%)$ & 0.79 & $47(19 \%)$ \\
\hline
\end{tabular}

Values are presented as $n(\%)$ unless otherwise noted.

${ }^{*} P=0.01$, chi-square test with Yates' correction.

CAP, community-acquired pneumonia; NRP, nonresponsive pneumonia; $S D$, standard deviation. 
Table 3. Comparison of recorded presenting signs and diagnostic testing of subjects with CAP: cases vs. controls

\begin{tabular}{|c|c|c|c|c|}
\hline Sign/diagnostic test & $\begin{array}{l}\text { NRP cases } \\
\quad(\mathrm{N}=85)\end{array}$ & $\begin{array}{l}\text { CAP controls } \\
\quad(\mathrm{N}=165)\end{array}$ & $\begin{array}{l}\text { Odds } \\
\text { ratio }\end{array}$ & $\begin{array}{l}\text { All subjects } \\
(\mathrm{N}=250)\end{array}$ \\
\hline Mean max. temperature $\pm \mathrm{SD},{ }^{\circ} \mathrm{F}$ & $\begin{array}{c}99.6 \pm 2.0 \\
(n=61)\end{array}$ & $\begin{array}{c}99.5 \pm 1.7 \\
(n=115)\end{array}$ & & $\begin{array}{c}99.5 \pm 1.8 \\
(n=176)\end{array}$ \\
\hline Mean heart rate $\pm S D$, bpm & $\begin{array}{c}87.5 \pm 20.1 \\
(n=70)\end{array}$ & $\begin{array}{c}85.2 \pm 15.8 \\
(n=133)\end{array}$ & & $\begin{array}{c}86.0 \pm 17.4 \\
(n=203)\end{array}$ \\
\hline Median respiratory rate, rpm & $20.0^{*}(n=47)$ & $18.0(n=66)$ & & $18.0(n=113)$ \\
\hline Median oxygen saturation, \% & $93.5^{\dagger}(n=44)$ & $96.0(n=77)$ & & $95.0(n=121)$ \\
\hline Decreased breath sounds & $11(13 \%)$ & $36(22 \%)$ & 0.53 & $47(19 \%)$ \\
\hline Dullness to percussion & $3(4 \%)$ & $4(2 \%)$ & 1.47 & $7(3 \%)$ \\
\hline Rales/crackles & $23(27 \%)$ & $57(35 \%)$ & 0.70 & $80(32 \%)$ \\
\hline Rhonchi & $17(20 \%)$ & $31(19 \%)$ & 1.08 & $48(19 \%)$ \\
\hline Wheezes & $26(31 \%)$ & $57(35 \%)$ & 0.84 & $83(33 \%)$ \\
\hline Chest X-ray & $68(80 \%)$ & $112(68 \%)$ & 1.89 & $180(72 \%)$ \\
\hline Chest CT scan & $4(5 \%)$ & $5(3 \%)$ & 1.58 & $9(4 \%)$ \\
\hline White blood cell count & $21(25 \%)$ & $21(13 \%)$ & $2.25^{\ddagger}$ & $42(17 \%)$ \\
\hline Sputum culture & $1(1 \%)$ & $2(1 \%)$ & 0.97 & $3(1 \%)$ \\
\hline
\end{tabular}

Values are presented as $n(\%)$ unless otherwise noted.

${ }^{*} P<0.05$, Mann-Whitney test.

${ }^{\dagger} P=0.02$, Mann-Whitney test.

${ }^{\ddagger} P=0.03$, chi-square test with Yates' correction.

CAP, community-acquired pneumonia; CT, computed tomography; NRP, nonresponsive pneumonia; SD, standard deviation.

3 controls had Legionella antigen testing, 3 controls had rapid influenza testing, and 1 control had testing for endemic fungi. There was no significant difference in the proportion of cases treated with antibiotics at the initial visit compared to controls (73/85 [86\%] vs. 155/165 [94\%], $\mathrm{P}=0.06$; Table 4).

All 85 of the NRP patients and $72 \%(n=119)$ of control patients received a follow-up clinical visit. Control patients who did not receive a follow-up visit had a mean age of $46.9 \pm 16$ years, had a current and former smoking rate of $24 \%$ and $13 \%$, respectively, and an asthma rate of $24 \%$. Rates of all other comorbid conditions were less than the mean for all 165 control patients. The average elapsed time for the first followup visit did not differ between groups (7.8 vs. 7.9 days). A second follow-up visit was made by $37 \%$ of controls and $86 \%$ of cases, and elapsed times did not differ (13.0 vs. 12.6 days).

At the first follow-up visit, as one might expect, a chest X-ray was ordered more often for cases $(55 \%)$ than controls $(26 \%, \mathrm{P}<0.001)$. Ultimately, $41 \%$ of eligible unique controls and $72 \%$ of cases received chest X-ray at the first or second follow-up visit. Ultimately, $10 \%$ of unique controls and $28 \%$ of cases received a computed tomography scan of the chest at the first or second follow-up visit. Referral for bronchoscopy occurred in $0.6 \%(1 / 165)$ of controls and $7 \%(7 / 85)$ of cases. This examination revealed bronchiolitis obliterans in the 1 control subject. Bronchoscopy was unrevealing in 2 of the cases, but led to a diagnosis of lung carcinoma in 2 cases, a diagnosis of tracheobronchomalacia in another, and diagnoses of Haemophilus parainfluenzae pneumonia and pseudomonal pneumonia, respectively, in the remaining 2 cases. A higher proportion of cases had an antibiotic change at the first $(62 \%$ vs. $15 \%$, $\mathrm{P}<0.001)$ or second follow-up visit $(47 \%$ vs. $5 \%$, $\mathrm{P}<0.001)$.

Multivariable binary logistic regression models, utilizing those predictor variables significantly associated on univariable analysis, revealed three main predicators of NRP: former smoker (odds ratio 2.27 
Table 4. Antibiotic regimen prescribed at initial visit

\begin{tabular}{|c|c|c|}
\hline Original antibiotic* & $\begin{array}{c}\text { NRP } \\
\text { cases } \\
(\mathrm{N}=85)\end{array}$ & $\begin{array}{c}\text { CAP } \\
\text { controls } \\
(\mathrm{N}=165)\end{array}$ \\
\hline No antibiotic & $9(11 \%)$ & $8(5 \%)$ \\
\hline Extended spectrum macrolide & $28(33 \%)$ & $63(38 \%)$ \\
\hline Quinolone & $30(35 \%)$ & $71(43 \%)$ \\
\hline $\begin{array}{l}\text { Amoxicillin or amoxicillin/clavulanic } \\
\text { acid }\end{array}$ & $5(6 \%)$ & $12(7 \%)$ \\
\hline Cephalosporin (oral) & $2(2 \%)$ & $4(2 \%)$ \\
\hline Doxycycline & $1(1 \%)$ & $2(1 \%)$ \\
\hline $\begin{array}{l}\text { Intravenous antibiotics (including } \\
\text { ceftriaxone) }\end{array}$ & $8(9 \%)$ & $7(4 \%)$ \\
\hline Sulfamethoxazole/trimethoprim & $1(1 \%)$ & 0 \\
\hline Penicillin & $1(1 \%)$ & 0 \\
\hline
\end{tabular}

* 5 cases were on two or more first-line antibiotics;

4 controls were on two or more first-line antibiotics.

$C A P$, community-acquired pneumonia; NRP, nonresponsive pneumonia.

[95\% confidence interval 1.23-4.18], $\mathrm{P}=0.009$ ), initial presentation to urgent care $(2.10$ [1.13-3.91], $\mathrm{P}=0.019)$ and symptoms of myalgia (2.79 [1.41-5.52], $\mathrm{P}=0.003)$. Other univariable associations were not significantly associated with NRP in this model.

The final diagnoses for controls and cases are summarized in Table 5. A specific organism or etiologic agent was not identified for the majority of patients with CAP. Seven case patients were ultimately diagnosed with something other than pneumonia (two with acute bronchitis, two with asthma/bronchospasm and one each with pulmonary fibrosis, Mycobacterium avium and upper respiratory infection), and three cases were deemed postobstructive pneumonia related to non-small cell lung cancer. Two control patients were ultimately diagnosed with acute bronchitis and cardiomyopathy, respectively, rather than pneumonia.

\section{DISCUSSION}

Clinical stability and response to initial treatment of CAP is affected by several factors, including severity of the disease, comorbid conditions, local and other end-organ complications, and nonadherence to treatment guidelines. ${ }^{7,8,11}$ Criteria for clinical stability,
Table 5. Final diagnosis of controls and cases

\begin{tabular}{lcc}
\hline Final diagnosis & $\begin{array}{c}\text { CAP } \\
\text { controls }\end{array}$ & $\begin{array}{c}\text { NRP } \\
\text { cases }\end{array}$ \\
\hline CAP or pneumonia NOS & 152 & 60 \\
Post-obstructive pneumonia $^{\text {Anaerobic* }}$ & 0 & 3 \\
Mycoplasma* $^{*}$ & 0 & 3 \\
Viral $^{*}$ & 6 & 1 \\
Cryptogenic $_{\text {Eosinophilic }}$ & 3 & 0 \\
Legionella $_{\text {MRSA }}$ & 1 & 1 \\
Klebsiella pneumoniae & 0 & 1 \\
Haemophilus influenzae & 0 & 2 \\
Pseudomonas & 0 & 1 \\
Streptococcus pneumoniae & 0 & 1 \\
Not pneumonia & 0 & 2 \\
Total & 0 & 2 \\
\hline
\end{tabular}

${ }^{*}$ Clinically suspected, not cultured.

$C A P$, community-acquired pneumonia; MRSA, methicillinresistant Staphylococcus aureus; NOS, not otherwise specified; NRP, nonresponsive pneumonia.

as defined by Halm and others, includes normalized vital signs, adequate oxygen saturation on room air and oral intake, and normal mental status. ${ }^{19,20}$ However, these criteria were essentially determined through analysis of hospitalized patients and intended for use in hospitalized pneumonia patients, not patients initially evaluated and treated as outpatients. For purposes of our study, we defined NRP in patients initially evaluated by primary care clinicians in the ambulatory setting as individuals with CAP who had worsening vital signs, symptoms or clinical findings after 4 days, or who did not improve within 10 days, of antibiotic treatment.

While we agree with Menendez et al. that the issue of nonresolving pneumonia is complex and the definition somewhat arbitrary, we also agree that the proposed definition of NRP listed in his review, "a clinical syndrome in which local infiltrates clearly begin with some clinical association of acute pulmonary infection (that is, fever, expectoration, malaise and/or dyspnea) and do not resolve in the expected time," is too 
vague. ${ }^{21}$ Our choice of a 4-day window of antibiotic treatment in which there is no further deterioration of vital signs, symptoms or clinical findings is consistent with a prospective study of hospitalized CAP patients by the Menendez group, which observed a median of 4 days of antibiotic treatment to clinical stability using criteria similar to Halm. ${ }^{16}$ Additionally, others have defined NRP in hospitalized CAP patients as those with lack of response after 3 to 4 days of appropriate antibiotic treatment, often with clinical deterioration. . $^{7,8,9,17}$

The second portion of our definition of NRP, 10 days of antibiotic therapy without improvement, is consistent with the observation that $90 \%$ of pneumonia-related hospitalizations in a cohort of 944 CAP patients who were treated as outpatients occurred within 10 days of treatment. ${ }^{22}$ These same authors concluded that "the incidence of hospitalization within 10 days of beginning outpatient treatment for CAP is a reasonable screening tool for unsatisfactory quality of care in this illness." Similarly, Low et al. also defined NRP as no clinical improvement or worsening despite 10 days of antibiotic therapy. ${ }^{23}$

Despite a conservative definition of NRP, it was commonly encountered in our health system among patients with CAP (34\%). This figure is significantly higher than the 6-25\% incidence rates reported in reviews of almost exclusively hospital-based studies. ${ }^{7,8,11}$ A prospective study of 1,424 patients admitted to 15 Spanish hospitals documented treatment failure in $15.1 \%$ of cases. Early treatment failure, defined as failure within 72 hours, occurred in $62 \%$ of these failures. ${ }^{15}$ This same group prospectively studied 453 patients with CAP admitted to two Spanish hospitals and observed treatment failure in $18 \% .{ }^{17}$ Roson et al. performed an observational study of 1,383 CAP patients hospitalized in Barcelona. ${ }^{9}$ Early failure, defined as lack of response or worsening of clinical or radiologic status at 48-72 hours requiring changes in antibiotic therapy or invasive procedures, was experienced by $6 \%$ of these patients, predominantly due to progressive pneumonia. Another $18 \%$ remained febrile at $48-72$ hours, but most responded without change in antibiotic therapy. A recent retrospective study of 32,324 patients with CAP hospitalized in non-ICU settings in more than
100 U.S. hospitals observed a $14.6 \%$ initial treatment failure rate. Treatment failure was defined as receipt of new antibiotics, exclusive of culture-directed equivalent substitutions. ${ }^{10}$ In the aforementioned study of 944 CAP cases treated as outpatients, 7.5\% of patients were subsequently hospitalized within 30 days. $^{22}$ This cohort, however, was a methodically selected low-risk population chosen for ambulatory treatment.

Causes of our relatively high rate of NRP among patients with CAP are not entirely clear from this study. In other studies causes of NRP included (but were not limited to) the following: overwhelming or progressive pneumonia, extrapulmonary spread, unusual, specific or resistant organisms, significant comorbid conditions, older age, incorrect antibiotic therapy, and malignant or nonmalignant clinical entities that present in conjunction with pneumonia or mimic the presentation of pneumonia (Table 6). ${ }^{7-10,15,16,23,24}$ These previous studies involved almost exclusively hospitalized patients. However, in the previously referenced cohort of selected CAP patients treated as outpatients (with failure defined as need for hospitalization), those requiring hospitalization were older, of higher baseline risk class and had chronic cardiac and/or lung disease compared to those not hospitalized. ${ }^{22}$

Initial severity is an important predictor of slow response of CAP to treatment and often included in the various clinical scoring systems such as Pneumonia Severity Index, CURB-65 or SMART-COP., ${ }^{7,85-27}$ Age, which was not statistically significant in our multivariable analysis, is included in some pneumonia severity prediction tools; however, cutoffs range from 65 to 80 years..$^{25,26}$ In addition to comorbid conditions and vital signs, certain symptoms (e.g. dyspnea, confusion) may predict NRP. ${ }^{16}$ Except for former smoking history, myalgia, respiratory rate and pulse oximetry readings (in those for whom this data was recorded), there were no differences in presenting signs, symptoms and comorbid conditions between cases and controls in our study. Nonetheless, cases received more diagnostic tests at the first visit. Perhaps this was a result of uncaptured variables such as an overall clinical impression of greater degree of illness among the cases. 
Table 6. Causes of nonresponsive pneumonia ${ }^{7-10,15,16,23,24}$

\begin{tabular}{|c|c|}
\hline Host factors & $\begin{array}{l}\text { Poor pulmonary toilet } \\
\text { Local or generalized immune deficiency } \\
\text { Major comorbid conditions } \\
\text { Smoking } \\
\text { Chest or lung anatomic abnormalities }\end{array}$ \\
\hline $\begin{array}{l}\text { Infections and } \\
\text { complications }\end{array}$ & $\begin{array}{l}\text { Resistant organisms } \\
\text { - Pseudomonas aeruginosa } \\
\text { - Methicillin-resistant Staphylococcus } \\
\text { aureus (MRSA) } \\
\text { - } \beta \text {-lactamase-producing } \\
\text { Enterobacteriaceae } \\
\text { Inherently slow-resolving organisms } \\
\text { (e.g. Legionella sp.) } \\
\text { Unusual microorganisms } \\
\text { - Mycobacterium sp. } \\
\text { - Nocardia sp. } \\
\text { - Fungi (Aspergillus, Blastomyces, } \\
\text { Histoplasma, Coccidioides) } \\
\text { - Pneumocystis jirovecii } \\
\text { - Anaerobes } \\
\text { Viruses } \\
\text { - Influenza A and B } \\
\text { - Respiratory syncytial virus } \\
\text { - Adenovirus } \\
\text { - Human metapneumovirus } \\
\text { Complications of pneumonia } \\
\text { - Empyema } \\
\text { - Abscess or necrotizing pneumonia } \\
\text { - Incotatatic infection } \\
\text { - Incorrect dose } \\
\text { - Matient intolerance or nonadherence }\end{array}$ \\
\hline Noninfections & $\begin{array}{l}\text { Neoplasms } \\
\text { Acute respiratory distress syndrome } \\
\text { Pulmonary edema } \\
\text { Pulmonary embolism } \\
\text { Pulmonary hemorrhage } \\
\text { Pulmonary fibrosis } \\
\text { Cryptogenic organizing pneumonia } \\
\text { Eosinophilic pneumonia } \\
\text { Sarcoidosis } \\
\text { Collagen vascular disease } \\
\text { Vasculitis } \\
\text { • Granulomatosis with polyangiitis } \\
\text { (Wegener's) }\end{array}$ \\
\hline
\end{tabular}

The association of myalgia with NRP is interesting. While myalgia may be found among those with atypical organisms and in some cases of invasive Streptococcus pneumoniae infections, ${ }^{28}$ it is common in patients with influenza, an entity not responsive to antibacterial agents and which often yields more severe or prolonged symptoms. ${ }^{29}$ Historically, Streptococcus pneumoniae has been the most commonly identified bacterial etiologic agent of CAP in adults. ${ }^{25}$ Haemophilus influenzae, Legionella spp., Staphylococcus aureus (including methicillin-resistant strains $[\mathrm{MRSA}])^{26}$ and gram-negative bacilli cause a minority of CAP cases. In a Canadian study of CAP patients who were primarily managed as outpatients, Mycoplasma pneumoniae, respiratory viruses and Chlamydophila pneumoniae were also common etiologies; however, viruses were not sought. ${ }^{30}$ In a recent comprehensive study of the etiologic agents of CAP in hospitalized adults with radiologic evidence of pneumonia in Chicago and Nashville, a pathogen was detected in $38 \%$ of all cases; one or more viruses were detected in $23 \%$, bacteria in $11 \%$, bacterial and viral pathogens in $3 \%$ and fungal or mycobacteria in $1 \% .{ }^{31}$ A similar study in New Zealand observed a $29 \%$ viral presumed etiology in hospitalized patients with CAP. Intriguingly, myalgia was associated with pneumonia caused by a respiratory virus and with influenza pneumonia. ${ }^{32}$ Perhaps our study population of CAP patients initially evaluated by primary care clinicians in ambulatory settings includes a significant proportion of patients with primary viral pneumonia. Such individuals would be expected to have a slow or nonresponsive course following onset of antibiotic treatment (i.e. NRP) ${ }^{33}$ and may have associated myalgia.

The majority of primary care clinicians in our study ordered a chest radiograph - a " $\mathrm{C}$ " recommendation (consensus, expert opinion) in this setting to confirm clinically suspected $\mathrm{CAP}^{25}$ - but no further testing when CAP was diagnosed in an ambulatory setting. In a similar patient population, chest radiographs were ordered in $87.5 \%$ of cases given the diagnosis of CAP by ambulatory primary care clinicians, ${ }^{34}$ a figure somewhat higher than in our study (72\%). It is also a " $\mathrm{C}$ " recommendation that evaluation for specific pathogens that would alter standard empiric therapy should be performed on the basis of clinical 
and epidemiological grounds; testing is usually not required in outpatients. ${ }^{25}$ This more pragmatic approach may decrease unnecessary diagnostic testing but could potentially delay confirmation of the specific disease or misdiagnose some patients with similar symptoms but different illnesses.

In our study, initial empiric antibiotic regimens were generally within contemporary treatment guidelines. ${ }^{24,25}$ Adherence to these guidelines did not seem to differ between cases and controls and does not seem to explain the high rate of NRP. The majority of patients who fulfilled our definition of NRP had an additional chest radiograph and a change of antibiotics at the first follow-up visit, actions generally supported by expert opinion. ${ }^{7,25,26}$

\section{Limitations}

Our retrospective study design allowed for the observation of clinician behavior and disease progression regarding patients with CAP presenting to a primary care clinic, without introducing the Hawthorne effect, ${ }^{35}$ but also created certain limitations. Some pertinent data were not available in medical records, and patients did not return for follow-up at defined intervals or at all in some instances. Missing data could introduce information bias; however, there was no indication these limitations were more prevalent among cases than controls. Control patients who did not make return visits may have skewed the results; however, these were generally healthy patients deemed likely to recover and who did not require a return visit by the treating clinician.

Additionally, although we made a clear definition of NRP, obtaining a clear picture of the onset of the disease and eradication of the illness from the clinical records was difficult for some patients. It is important to emphasize that this was a study of patients given the initial diagnosis of CAP by a primary care clinician in an ambulatory setting. Subsequent care may have included inpatient or outpatient consultation or management by specialists. Some patients did not undergo initial radiologic study to confirm the diagnosis, and some did have negative reports. The latter may not preclude the diagnosis of pneumonia given the lag of radiologic findings in early pneumonia. ${ }^{36}$ Nonetheless, patients with nonpneumonic viral infections, for example, may have been included in the study cohort, and these entities may have contributed to the percentage of patients with NRP, given the propensity for the most common symptom, cough, to last up to 3 weeks, ${ }^{37}$ and particularly given the mismatch of cough duration with patient expectations. ${ }^{38}$ Lastly, some patients with self-limited CAP may have been missed on presentation with respiratory symptoms. ${ }^{37}$

This study presents opportunities for further research. Careful prospective studies could perhaps define a more useful scoring system - based on presenting signs, symptoms and comorbid conditions - for predicting NRP in patients with CAP treated in the ambulatory setting. A number of biomarkers have been considered useful adjuncts for the determination of bacterial pneumonia diagnosis, severity and treatment response in some, but not all, studies..$^{71,26,39-41}$ Further investigations are certainly needed to confirm the utility of these tests in the patient with CAP who is evaluated as an outpatient. Similarly, the role of rapid diagnostic tests for specific respiratory pathogens in the outpatient setting is still being defined. ${ }^{42}$ Future research could explore their utility in CAP to help assign etiology and to determine proper treatment and expectations regarding response at the time of presentation.

\section{CONCLUSIONS}

When primary care clinicians initially diagnose community-acquired pneumonia in an ambulatory clinic, the majority order chest radiographs but only a small minority order additional testing for specific etiologic agents. Risk factors for nonresponsive pneumonia among those with CAP identified in this study included former smoking history, symptoms of myalgia and presentation to urgent care. The presence of myalgia may be too nonspecific to be useful as a predictor of NRP; however, it may point toward a viral etiology, one likely to be nonresponsive to antibiotic therapy. Careful prospective studies are needed to determine if the use of serum biomarkers and/or targeted rapidly available molecular tests for specific etiologic organisms - perhaps in conjunction with presenting signs and symptoms - at the initial visit for CAP predicts or prevents NRP in the primary care ambulatory setting. 


\section{Patient-Friendly Recap}

- Community-acquired pneumonia (CAP) is a common infectious disease.

- When initial treatment with antibiotics fails, a CAP patient is said to have nonresponsive pneumonia (NRP). There are a number of reasons for NRP.

- The authors reviewed cases of NRP in patients diagnosed in an outpatient clinic (as opposed to in a hospital setting).

- They found NRP occurs more frequently than previously thought, and may be more common among pneumonia patients who have muscle pain, present to urgent care or used to smoke.

\section{Acknowledgments}

The authors acknowledge Olayinka A. Olowoyeye, $\mathrm{MD}$, for pilot chart review yielding the first 28 subjects, and four anonymous reviewers for manuscript suggestions.

\section{Conflicts of Interest}

None.

\section{References}

1. File TM Jr, Marrie TJ. Burden of community-acquired pneumonia in North American adults. Postgrad Med. 2010;122:130-41. CrossRef

2. Stanton MW. Improving treatment decisions for patients with community-acquired pneumonia. Rockville, MD: Agency for Healthcare Research and Quality, Research in Action, July 2002, Issue 7. AHRQ Pub. No. 02-0033.

3. Fine MJ, Auble TE, Yealy DM, et al. A prediction rule to identify low-risk patients with community-acquired pneumonia. N Engl J Med. 1997;336:243-50. CrossRef

4. Fine MJ, Stone RA, Singer DE, et al. Processes and outcomes of care for patients with community-acquired pneumonia: results from the Pneumonia Patient Outcomes Research Team (PORT) cohort study. Arch Intern Med. 1999;159:970-80. CrossRef

5. Carratalà J, Fernández-Sabé N, Ortega L, et al. Outpatient care compared with hospitalization for community-acquired pneumonia: a randomized trial in low-risk patients. Ann Intern Med. 2005;142:165-72. CrossRef

6. van Vugt SF, Verheij TJ, de Jong PA, et al. Diagnosing pneumonia in patients with acute cough: clinical judgment compared to chest radiography. Eur Respir J. 2013;42:1076-82. CrossRef

7. Sialer S, Liapikou A, Torres A. What is the best approach to the nonresponding patient with community-acquired pneumonia? Infect Dis Clin North Am. 2013;27:189-203. CrossRef
8. Aliberti S, Blasi F. Clinical stability versus clinical failure in patients with community-acquired pneumonia. Semin Repir Crit Care Med. 2012;33:284-91. CrossRef

9. Rosón B, Carratalà J, Fernández-Sabé N, Tubau F, Manresa F, Gudiol F. Causes and factors associated with early failure in hospitalized patients with community-acquired pneumonia. Arch Intern Med. 2004;164:502-8. CrossRef

10. Oster G, Berger A, Edelsberg J, Weber DJ. Initial treatment failure in non-ICU community-acquired pneumonia: risk factors and association with length of stay, total hospital charges, and mortality. $J$ Med Econ. 2013;16:809-19. CrossRef

11. Tan JS. Nonresponses and treatment failures with conventional empiric regimens in patients with community-acquired pneumonia. Infect Dis Clin North Am. 2004;18:883-97. CrossRef

12. Torres A, Peetermans WE, Viegi G, Blasi F. Risk factors for community-acquired pneumonia in adults in Europe: a literature review. Thorax. 2013;68:1057-65. CrossRef

13. Aliberti S, Amir A, Peyrani P, et al. Incidence, etiology, timing, and risk factors for clinical failure in hospitalized patients with community-acquired pneumonia. Chest. 2008;134:955-62. CrossRef

14. Arancibia F, Ewig S, Martinez JA, et al. Antimicrobial treatment failures in patients with community-acquired pneumonia: causes and prognostic implications. Am J Respir Crit Care Med. 2000;162:154-60. CrossRef

15. Menéndez R, Torres A, Zalacaín R, et al. Risk factors of treatment failure in community acquired pneumonia: implications for disease outcome. Thorax. 2004;59:960-5. CrossRef

16. Menéndez R, Torres A, Rodríguez de Castro F, et al. Reaching stability in community-acquired pneumonia: the effects of the severity of disease, treatment, and the characteristics of patients. Clin Infect Dis. 2004;39:1783-90. CrossRef

17. Menéndez R, Cavalcanti M, Reyes $S$, et al. Markers of treatment failure in hospitalised community acquired pneumonia. Thorax. 2008;63:447-52. CrossRef

18. National Weather Service. National Weather Service Glossary. http://w1.weather.gov/glossary/. Accessed December 7, 2015.

19. Halm EA, Fine MJ, Marrie TJ, et al. Time to clinical stability in patients hospitalized with community-acquired pneumonia: implications for practice guidelines. JAMA. 1998;279:1452-7. CrossRef

20. Mandell LA, Wunderink RG, Anzueto A, et al. Infectious Diseases Society of America/American Thoracic Society consensus guidelines on the management of communityacquired pneumonia in adults. Clin Infect Dis. 2007;44 Suppl 2:S27-72. $\underline{\text { CrossRef }}$

21. Menéndez R, Perpiñá M, Torres A. Evaluation of nonresolving and progressive pneumonia. Semin Respir Infect. 2003;18:103-11.

22. Minogue MF, Coley CM, Fine MJ, Marrie TJ, Kapoor WN, Singer DE. Patients hospitalized after initial outpatient treatment for community-acquired pneumonia. Ann Emerg Med. 1998;31:376-80. CrossRef

23. Low DE, Mazzulli T, Marrie T. Progressive and nonresolving pneumonia. Curr Opin Pulm Med. 2005;11:247-52. CrossRef

24. Rome L, Murali G, Lippmann M. Nonresolving pneumonia and mimics of pneumonia. Med Clin North Am. 2001;85:1511-30. CrossRef

25. Watkins RR, Lemonovich TL. Diagnosis and management of community-acquired pneumonia in adults. Am Fam Physician. 2011;83:1299-306. 
26. Brar NK, Niederman MS. Management of communityacquired pneumonia: a review and update. Ther Adv Respir Dis. 2011;5:61-78. CrossRef

27. Metlay JP, Fine MJ. Testing strategies in the initial management of patients with community-acquired pneumonia. Ann Intern Med. 2003;138:109-18. CrossRef

28. Torres JM, Cardenas O, Vasquez, Schlossberg D. Streptococcus pneumoniae bacteremia in a community hospital. Chest. 1998;113:387-90. CrossRef

29. Treanor JJ. Influenza (including avian influenza and swine influenza). In: Bennett JE, Dolin R, Blaser MJ (eds). Mandell, Douglas, and Bennett's Principles and Practice of Infectious Diseases, Eighth Edition. Philadelphia, PA: Saunders Elsevier, 2015, pp. 2000-24.e6.

30. Marrie TJ, Poulin-Costello M, Beecroft MD, Herman-Gnjidic Z. Etiology of community-acquired pneumonia treated in an ambulatory setting. Respir Med. 2005;99:60-5. CrossRef

31. Jain S, Self WH, Wunderink RG, et al. Community-acquired pneumonia requiring hospitalization among U.S. adults. $N$ Engl J Med. 2015;373:415-27. CrossRef

32. Jennings LC, Anderson TP, Beynon KA, et al. Incidence and characteristics of viral community-acquired pneumonia in adults. Thorax. 2008;63:42-8. CrossRef

33. Almond MH, McAuley DF, Wise MP, Griffiths MJ. Influenzarelated pneumonia. Clin Med (Lond). 2012;12:67-70. CrossRef

34. Evertsen J, Baumgardner DJ, Regnery A, Banerjee I. Diagnosis and management of pneumonia and bronchitis in outpatient primary care practices. Prim Care Respir J. 2010;19:237-41. CrossRef

35. Mangione-Smith R, Elliott MN, McDonald L, McGlynn EA. An observational study of antibiotic prescribing behavior and the Hawthorne effect. Health Serv Res. 2002;37:1603-23. CrossRef
36. Bruns AH, Oosterheert JJ, El Moussaoui R, Opmeer BC, Hoepelman AI, Prins JM. Pneumonia recovery: discrepancies in perspectives of the radiologist, physician and patient. $J$ Gen Intern Med. 2010;25:203-6. CrossRef

37. van Vugt SF, Verheij TJ, de Jong PA, et al. Diagnosis pneumonia in patients with acute cough: clinical judgment compared to chest radiography. Eur Respir J. 2013;42:1076-82. CrossRef

38. Ebell MH, Lundgren J, Youngpairoj S. How long does a cough last? Comparing patients' expectations with data from a systematic review of the literature. Ann Fam Med. 2013;11: 5-13. CrossRef

39. van Vugt SF, Broekhuizen BD, Lammens C, et al. Use of serum $\mathrm{C}$ reactive protein and procalcitonin concentrations in addition to symptoms and signs to predict pneumonia in patients presenting to primary care with acute cough: diagnostic study. BMJ. 2013;346:f2450. CrossRef

40. Hopstaken RM, Muris JW, Knottnerus JA, Kester AD, Rinkens PE, Dinant GJ. Contributions of symptoms, signs, erythrocyte sedimentation rate, and $\mathrm{C}$-reactive protein to a diagnosis of pneumonia in acute lower respiratory tract infection. $\mathrm{Br} J \mathrm{Gen}$ Pract. 2003;53:358-64.

41. Flanders SA, Stein J, Shochat G, et al. Performance of a bedside C-reactive protein test in the diagnosis of communityacquired pneumonia in adults with acute cough. Am J Med. 2004;116:529-35. CrossRef

42. Caliendo AM, Gilbert DN, Ginocchio CC, et al. Better tests, better care: improved diagnostics for infectious diseases. Clin Infect Dis. 2013;57 Suppl 3:S139-70. CrossRef

(C) 2016 Aurora Health Care, Inc. 